University of Wollongong

Research Online

Faculty of Informatics - Papers (Archive)

Faculty of Engineering and Information

Sciences

June 2006

\title{
Location-Based Intelligence - Modeling Behavior in Humans using GPS
}

Katina Michael

University of Wollongong, katina@uow.edu.au

Andrew McNamee

University of Wollongong, am46@uow.edu.au

M G. Michael

University of Wollongong, mgm@uow.edu.au

Holly Tootell

University of Wollongong, holly@uow.edu.au

Follow this and additional works at: https://ro.uow.edu.au/infopapers

Part of the Physical Sciences and Mathematics Commons

\section{Recommended Citation}

Michael, Katina; McNamee, Andrew; Michael, M G.; and Tootell, Holly: Location-Based Intelligence Modeling Behavior in Humans using GPS 2006.

https://ro.uow.edu.au/infopapers/386 


\title{
Location-Based Intelligence - Modeling Behavior in Humans using GPS
}

\begin{abstract}
This paper introduces the notion of location-based intelligence by tracking the spatial properties and behavior of a single civilian participant over a two-week study period using a global positioning system (GPS) receiver, and displaying them on a geographic information system (GIS). The paper clearly shows the power of combining speed (S), distance (D), time (T) and elevation (E) data with the exact longitude and latitude position of the user. The issues drawn from the observation and the civilian's personal diary are useful in understanding the social implications of tracking and monitoring objects and subjects using GPS. The findings show that while GPS has been used in some very innovative ways, there are a plethora of ethical dilemmas associated with its use on civilians, even if they are requesting a given service and paying for its utilization. From the information recorded during the field observation, a number of inherent technical limitations in GPS were identified which add to the complexity of such related areas as law and commerce. In conclusion, while the benefits of GPS for specific applications is apparent, safeguards need to be put in place to ensure that information gathered by the GPS is not misused or abused. One can envisage that if the wrong hands obtain location information records for individual subscribers that the potential exposure and risk might be even greater than that of stolen credit cards.
\end{abstract}

\section{Keywords}

Location-based surveillance, Tracking, Monitoring, Travel Logs, Intelligence, Ethics, Uberveillance

\section{Disciplines}

Physical Sciences and Mathematics

\section{Publication Details}

This conference paper was originally published as Michael, $K$, McNamee, A, Michael, MG and Tootell, H, Location-Based Intelligence - Modeling Behavior in Humans using GPS, in Proceedings of the International Symposium on Technology and Society, New York, 8-11 June 2006. Copyright IEEE Computer Society. 


\title{
Location-Based Intelligence - Modeling Behavior in Humans using GPS
}

\author{
Katina Michael, Andrew McNamee, M.G. Michael, Holly Tootell \\ School of Information Technology and Computer Science, University of Wollongong \\ \{katina,am46,mgm,holly\}@uow.edu.au
}

\begin{abstract}
This paper introduces the notion of location-based intelligence by tracking the spatial properties and behavior of a single civilian participant over a two-week study period using a global positioning system (GPS) receiver, and displaying them on a geographic information system (GIS). The paper clearly shows the power of combining speed $(S)$, distance $(D)$, time $(T)$ and elevation (E) data with the exact longitude and latitude position of the user. The issues drawn from the observation and the civilian's personal diary are useful in understanding the social implications of tracking and monitoring objects and subjects using GPS. The findings show that while GPS has been used in some very innovative ways, there are a plethora of ethical dilemmas associated with its use on civilians, even if they are requesting a given service and paying for its utilization. From the information recorded during the field observation, a number of inherent technical limitations in GPS were identified which add to the complexity of such related areas as law and commerce. In conclusion, while the benefits of GPS for specific applications is apparent, safeguards need to be put in place to ensure that information gathered by the GPS is not misused or abused. One can envisage that if the wrong hands obtain location information records for individual subscribers that the potential exposure and risk might be even greater than that of stolen credit cards.
\end{abstract}

\section{Introduction}

This paper considers the specific data elements that can be gathered by service providers about telecommunications customers subscribed to locationbased service (LBS) applications. Increasingly private companies are investing in location-based technologies for asset, animal and people tracking. Depending on the type of technology in use, the level of accuracy in terms of identifying the outdoor position of the subscriber can vary from cell-based identification to nearest landmark, to the pinpoint longitude and latitude coordinates of an object or subject. The application context is also important- is information being gathered about employees by an employer or is the use of the technology a voluntary option for the subscriber or their caretaker. Till now, there have been only a few cases which have ended in litigation over the accuracy of a location fix, but as the number of LBS adopters sets to grow for niche application areas, it is predicted that a greater number of conflicts may arise between the end-user and stakeholders. Liability is a key issue here, as is privacy [1].

\section{Location-based surveillance}

\subsection{Tracking people}

"Mobility is a basic and indispensable human activity that is essential for us to be able to lead independent lives on a daily basis" [2]. Someone who is moving can be tracked manually or digitally. The information being gathered as the end-user moves around can be considered a type of "electronic chronicle" [3]. To allow oneself to be tracked can be a voluntary act, but in most cases it is imposed by a third party who has some control over the end-user. Tracking is critical in the process "of people motion capture, people behavior control and indoor video surveillance" [4]. In this paper we do not consider location information gathered using indoor tracking techniques such as knowledge representation or models of temporal correlation, although these techniques could be complementary to outdoor GPS tracking. There are also other techniques for tracking humans based on AssistedGPS (A-GPS) [5], Wi-Fi technology such as the 'Human Tracking and Following' system [6], or embedded technologies [7] which all may become used in the future as a replacement or contingency technique to GPS. The Wi-Fi tracking approach employs an obtrusive technique requiring the end-user to employ active beacons on their body, as opposed to vision systems which are generally unobtrusive. In like manner, a GPS receiver in the form of a watch or handheld device clipped to a belt can be considered obtrusive [8].

\subsection{Storing tracking data}

Tracking data gathered by a GPS, such as route or point information, can be spatially represented in a geographic information system (GIS). The GIS may contain multiple layers of information, from civic data to administrative political data, statistical information and 
even non-earth unit data. The GIS can store trajectory data that is based on assumptions related to the end-user's historical speed and direction data, and static road/path segment information. Related to this idea is the notion of "digital trail libraries", in effect the study of overlapping GPS trails and their digital storage [9]. Morris et al. explain that GPS track logs, are sequences of precise locations created by dropping a breadcrumb. While Morris' paper focuses on GPS for recreational activity, there is the potential for "private" track logs to be compared in order to find originating and terminating points of interaction between people. The outcomes of such an analysis fall into the category of location-based intelligence. Consider the potential for "collision” alerts of persons of interest. Access to the tracking data of an end-user's records requires strict policing. Hengartner and Steenkiste (2005) reaffirm that "[l]ocation is a sensitive piece of information" and that "releasing it to random entities might pose security and privacy risks" [10]. They emphasize the need for individual and institutional policies and the importance of formal models of trust.

\section{Methodology}

One way to deduce some of the unforeseen consequences of GPS-based human tracking is to experience the process first hand. In this pilot study, a civilian participant tracked themselves for a period of 2 weeks using a GPS 24/7. Participant observation is where the observer "seeks to become some kind of member of the observed group" [11]. For the purposes of this study the participant represents individuals who would have their movements tracked and monitored by a third party. Measures need to be taken to ensure the participant's normal activities are not impacted in any way by carrying the GPS.

Two sets of data are to be gathered throughout this observational study: geographical co-ordinates and diary logs (table 1). The geographical coordinates will be collected through the means of a GPS device as quantitative data. However, in order to interpret this data, GIS software will be used to transform co-ordinates into comprehensible geolocations. The daily diary logs will be collected as complementary qualitative data. Each day during the study the participant will record any thoughts and opinions they may have with respect to being tracked.

\subsection{Set-up}

The following guidelines were used in the pilot study:

- Daily activities - at the start of each day the GPS device is turned on as soon as the participant leaves their place of residence. At the end of each day the device is switched off.
- Carrying the GPS device - the device is carried in the participant's bag or pocket while walking. When driving, the device is placed securely in a dock.

- Tracking node limitation - the device is only capable of collecting 2000 tracking nodes at a time. While this is more than enough for a single day of tracking it is not enough for more than one day. Care must be taken to ensure that track data is erased at the end of each day so there will be enough memory the following day.

- Getting a signal - it takes about one minute to get a signal, so when the device is first turned on the user will have to wait until a signal is detected.

- Indoors - the device looses its signal when indoors so when the signal is lost at a certain location it will be assumed that the user is indoors.

- Battery life - the manual indicates that the device can get up to 14 hours of usage on two AA batteries. Rechargeable batteries do not have enough power to keep the GPS device running throughout an entire day. Non-rechargeable batteries will be replaced when they are running low.

Table 1- Observational Instruments

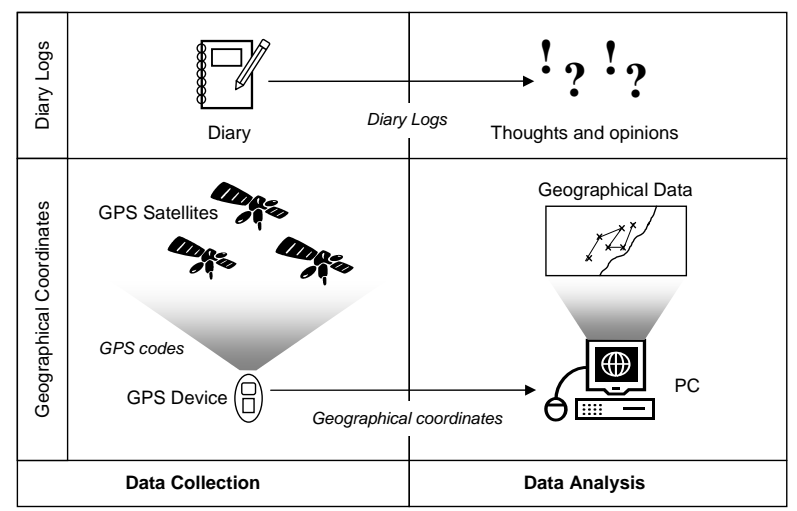

\section{Observational study}

\subsection{Digital breadcrumb}

An observational study was carried out to gain knowledge about the sensitivity of location information. This study involved a civilian participant who had their daily movements tracked from Monday 15th August 2005 to Sunday 28th August 2005. The participant is a 21 year old university student who works part-time and owns a vehicle. Each day during the two weeks of the study the participant carried a Magellan Meridian Gold handheld device either in a carry bag or pocket (see figure 1). The GPS device was setup to collect location data every three seconds. At the end of each day this data was uploaded into GIS software "DiscoverAus Streets \& Tracks" which 
was used to save and analyze the data. Throughout the entire study the observer stayed in the area of Wollongong, NSW, Australia.

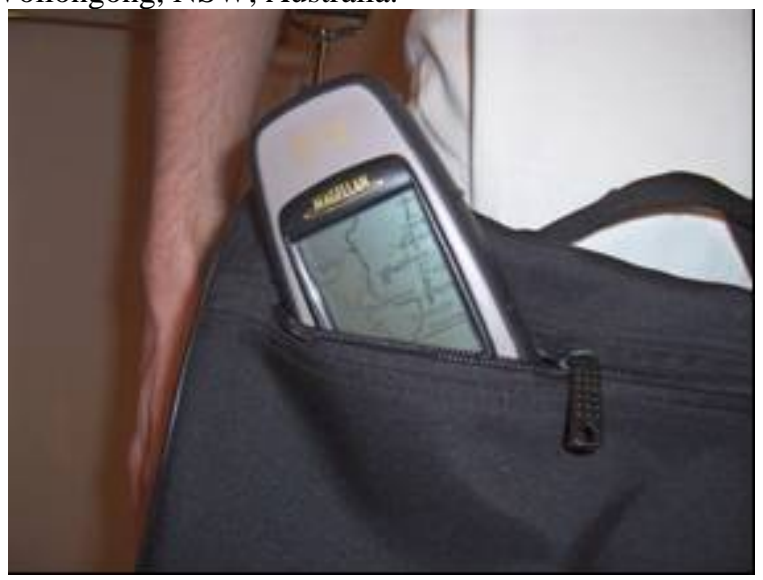

Figure 1 - Participant with Magellan GPS Device

A great deal of information was found out about the observer by tracking them over an extended period of time. From data coordinates it is easy to deduce information such as where the participant is located at a given point in time and the speed at which they are traveling. However, more invasive personal data, such as where the participant lives, his workplace and social activities can also be found. It is also possible to create detailed profiles about the participant based on his daily travel routines. For instance, the speed at which the participant is traveling can indicate the form of transport they are using. How long they spend at a location can determine the type of activities the participant is also engaged in.

Figure 2 shows the participant's movements on day 10 of the study (24th August 2005). On this day the participant traveled from their home to the University of Wollongong, and then to their place of work. This day is typical of other weekdays in the study as the most common locations traveled were to the participant's home, University and workplace. The user's daily track movements are indicated by the thicker lines (two closed loops connected by a highway). With the GIS software it is possible to play the participant's movements in real time, to get a step-by-step and magnified view of their whereabouts. Roads, highways, train tracks and trails are clearly presented in the map. Key locations, street names and suburb names are also shown on the map. Even more data could be gathered manually or purchased to overlay onto the current details. It would be interesting also to show intersecting trails of other members of the family during the same study period. Different types of "families" or "groups" would have different types of profiles, some lending themselves to greater location movement than others, with communities-of-interest
(CoI) varying widely from local, national and international travel.

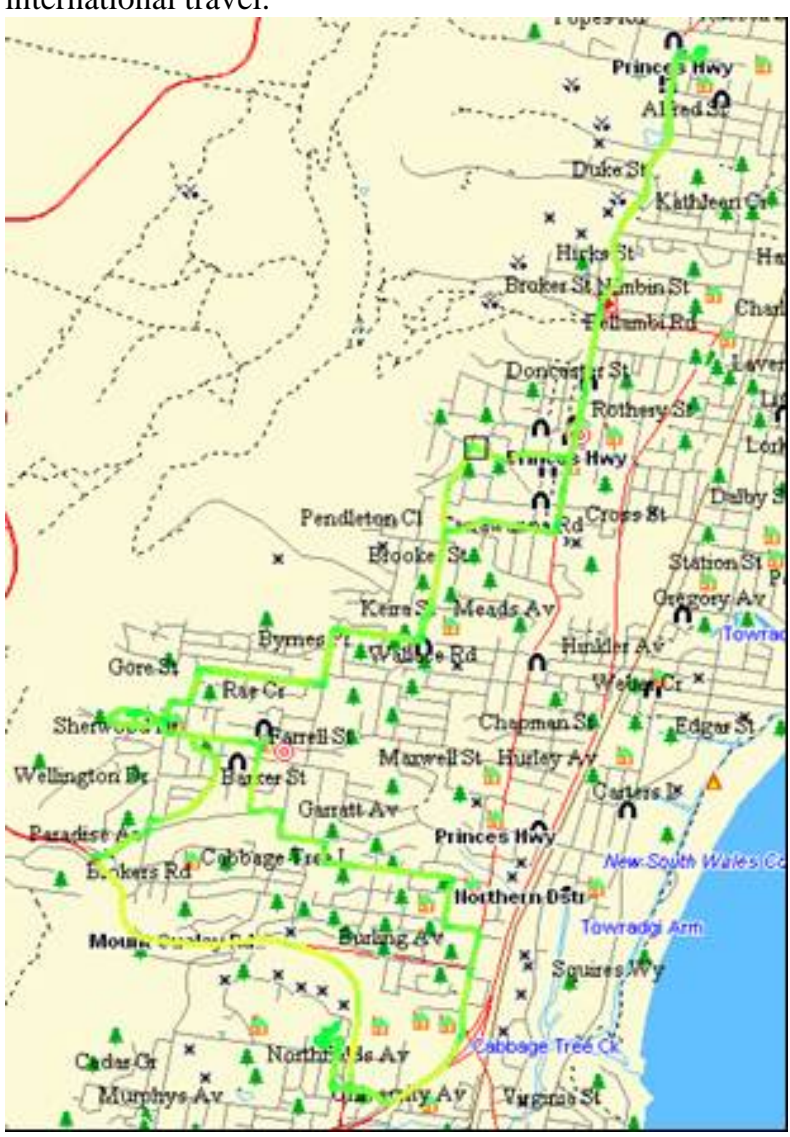

Figure 2 - Participant Track Data for the Study Period

\subsection{Graphical travel logs}

Graphical analysis of track data also gives indications of a person's travel habits and behavior, providing that all the data is accurate and free from errors. The following graphs (figures 3-6) are meaningful representations of speed, time, distance, and elevation data collected by the GPS.

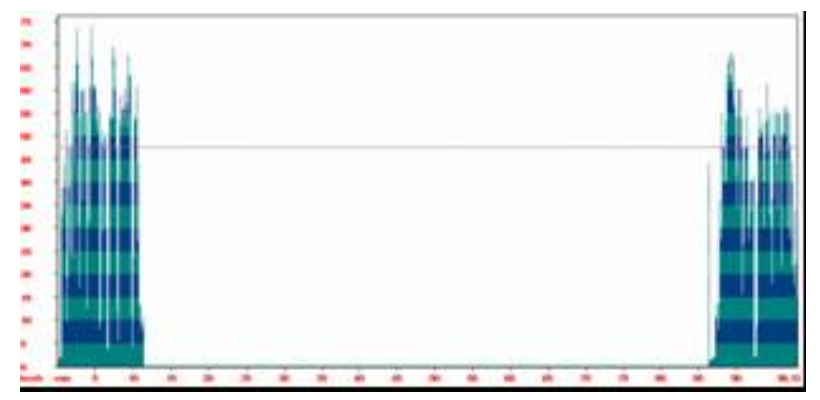

Figure 3 Time/Speed Graph: indicates speed at a specific time, when a person is traveling from one place to another, and how long the person spends at a given location. 


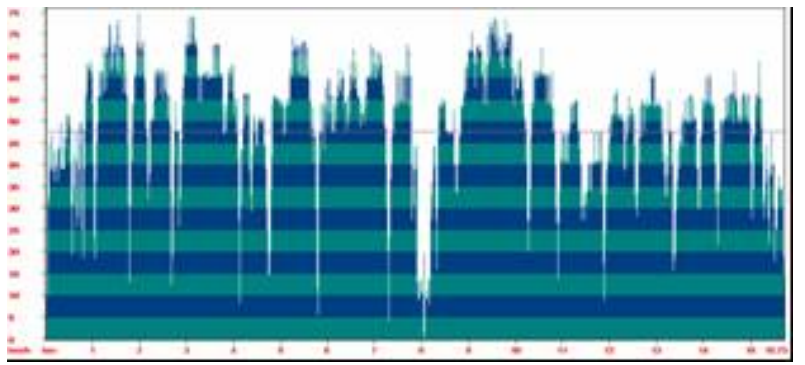

Figure 4: Distance/Speed Graph indicates speed at a specific point in a journey, and whether a person is in a vehicle or walking (i.e. form of transport).

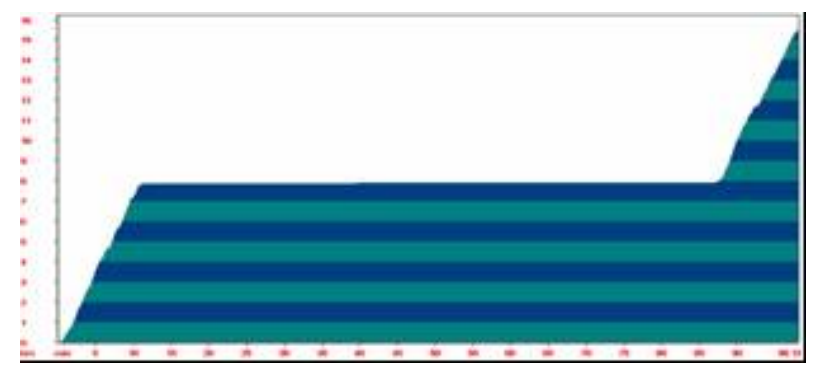

Figure 5: Time/Distance Graph indicates the length of time a person stays at a location, the length of time a person is on the move, and the number of places a person travels to.

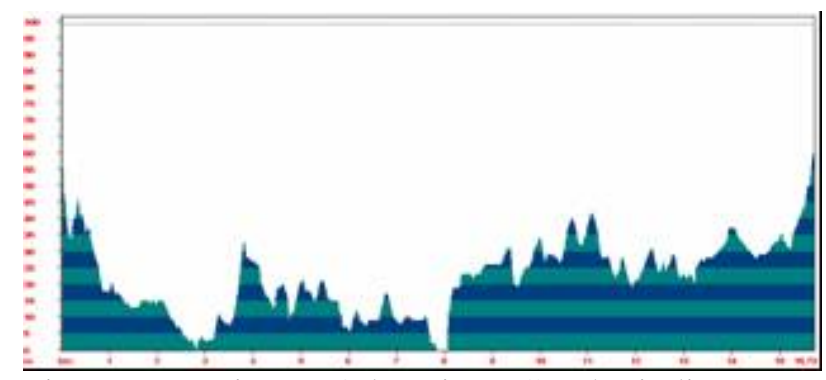

Figure 6: Distance/Elevation Graph indicates a person's location by comparing the elevation patterns with other data.

\section{GPS tracking issues}

\subsection{Accuracy}

Although not perfect in terms of accuracy of a given location fix, the GPS is generally perceived by civilians as being close to perfect. However, on several occasions in the observational study substantial errors occurred. Over the two weeks of the observational study there were six significant signal dropouts. During a signal dropout a person's location is not known. All of these dropouts occurred while the participant was traveling by car. It is likely that the GPS receiver was not positioned well enough to gain an accurate signal or traditional natural/physical factors affected the device. This kind of signal dropout could be costly in a real life scenario if a person's location was mandatory. There were also five significant speed miscalculations during the study. Speed is found by calculating the distance traveled between two points within a given time period. For example, on day 13 of the observational study the tracking information indicated a speed of $600 \mathrm{~km} / \mathrm{h}$ whilst in a moving vehicle. This was found by calculating the time and location differences between two subsequent tracking points. The collected GPS data indicated the participant had traveled 0.0479884332997 kilometres in 5 seconds.

Table 3- Summary of Geolocation Trail Data

Day 1. home $>$ uni $>$ home $>$ uni $>$ *signal dropout* Day 2. home $>$ uni $>$ home (speed miscalculation) Day 3. home $>$ uni $>$ home $>$ work $>$ home Day 4. home $>$ rta $>*$ signal dropout*> home $>$ *signal dropout $*>$ uni $>$ masterbuilders $>$ unibar $>$ home Day 5. home $>$ uni (speed miscalculation) $>*$ signal dropout* $>$ home

Day 6. home $>$ petrol station $>*$ signal dropout* $>$ work

Day 7. work $>$ home $>$ work $>$ home

Day 8 . home $>$ work $>$ home

Day 9. home $>$ uni (speed miscalculation) $>$ woolworths $>$ *signal dropout* $>$ home (speed miscalculation) $>$ work (gym) $>$ home

Day 10. home $>$ uni $>$ home $>$ work $($ gym $)>$ home

Day 11. home $>$ work

Day 12 . home $>$ work $($ gym $)>$ home $>$ work

Day 13. work $>$ home $>$ work $(\mathrm{bbc})>$ home (speed miscalculation)

Day 14. home

\subsection{Editing track data}

The GPS device used to collect location data stored tracking nodes which recorded location and time data every 3 seconds. GIS software was then used to create an entire track by joining each tracking node. However, the software also grants the user the option to add and edit tracking nodes. This feature is included to assist in navigation but could be used for other covert reasons. The use of GPS location data is surprisingly considered legitimate evidence in legal trials [12]. It is possible to convict an innocent man of a crime they did not commit by editing track data to falsify evidence. Stringent security and validation checks need to be set in place if authorities plan to use GPS track data as valid evidence in a court trial. 


\subsection{User travel behavior}

An analysis of the track data has shown that the participants' daily movements are quite similar each week (compare figures 7 and 8, 9 and 10) and is a reflection of their daily routines and behavior. The observer took the exact same travel route whenever they traveled to a known location, like home or work, even though there are alternate routes- reflecting how habitual some humans are. The track data also reflects the participant's behavior when they are running late for a meeting or deadline (i.e. the participant accelerated their speed while walking/driving). This kind of information can be used to create intelligent systems which can observe what a person is doing and then alert systems when their behavior is out of the ordinary.

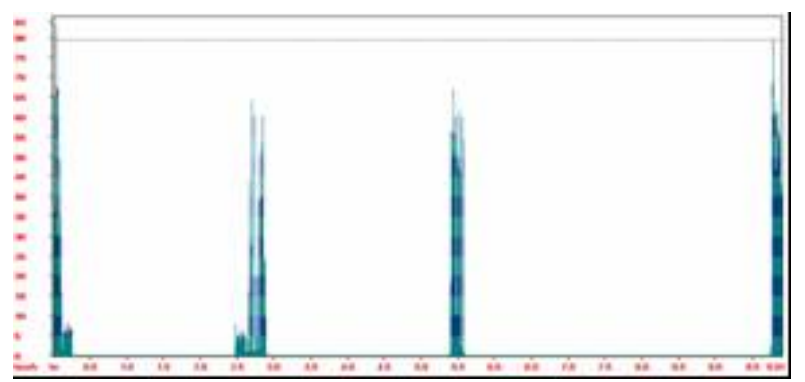

Figure 7: Time/Speed Graph (17 August 2005)

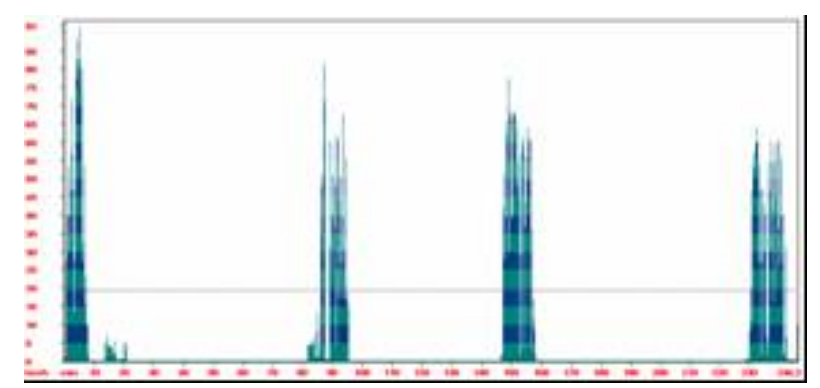

Figure 8: Time/Speed Graph (24 August 2005)

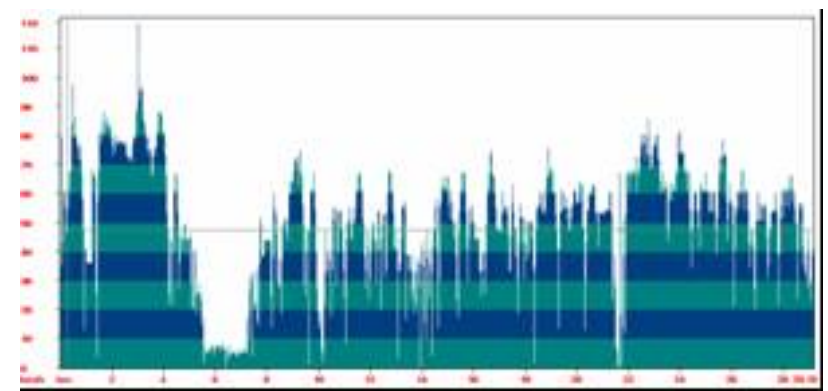

Figure 9: Distance/Speed Graph (17 August 2005)

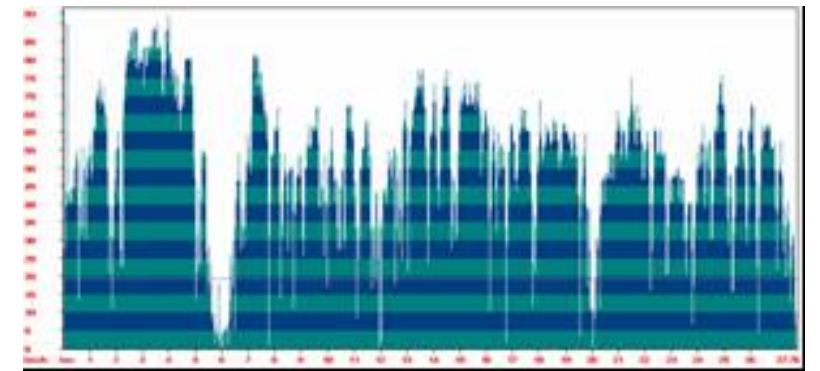

Figure 10: Distance/Speed Graph (24 August 2005)

Substantial similarities can be seen between like graphs, one week to the next. Both sets of time/speed graphs indicate the participant traveled on four occasions during the same day of the week, in consecutive weeks. The distance/speed graph shows similar patterns of traveling speed. In fact, the graphs of every single weekday were almost identical one week to the next, typical of a university student pattern of behavior. The weekends did not vary that much either- an opportunity to go to work, take a break for some socializing, and return home for further study.

\subsection{Detail of GIS}

The GIS software used, provided details on the roads, highways and the location of major landmarks but did not show any building data. There are however, databases like MapInfo's MapMarker or the Australian Geographical National Address File (G-NAF) that could be coupled with a telemarketing list to provide a rich background layer. In this project, little could be deduced from the user's location at certain longitude and latitude coordinates (apart from what the user provided) because the supporting database was absent. The level of detail in a GIS could be made scalable to correspond with its application context. In applications which require high resolution detail, the GIS could be setup to display roads, buildings and landmarks. Conversely, if little detail is needed it could show the user's location in relation to important landmarks.

\subsection{User awareness}

Several days into the study the user indicated that it was easy to forget about the fact they were being tracked or observed (see section 6). Any activity that is carried out at length could easily become routine. By the end of the study the user was not concerned about being tracked but was more concerned about having to carry the device around. If GPS were to be enforced on parolees as a deterrent to crime, the participant felt it might lose effectiveness as a tool in the longer term. 


\subsection{Outcomes of the observational pilot study}

This pilot study provided a practical perspective to the process of GPS tracking and proved that it can be accomplished with relative ease. The evidence suggests that tracking a person over an extended period of time is an invasion of privacy as GPS applications can track every detail of a person's movements. The probability of inaccuracies and the possibility of editing data poses questions about the reliability of such information. The effectiveness of GPS tracking in deterring crime may not be as great as first thought because the user may become blasé about its presence.

\section{Participant diary entries- narrative}

This section is taken verbatim from the participant's diaries made between Monday 15th August 2005 and Sunday 28th August 2005. It is important to highlight some of the end-user perceptions and attitudes towards the basic GPS tracking application.

\section{Day 1: Monday 15th August 2005}

Today was the first day of tracking. Throughout the day I was very conscious of the device I was carrying. Every time I left for a new location I would check if the device was working and if I was getting an accurate reading. A person being tracked would not be too concerned whether their receiver was working or not. Although a parolee with a faulty tracking device may face immediate repercussions.

\section{Day 2: Tuesday 16th August 2005}

It would seem that my primary objective is to simply carry the device, not to track my movements. I rarely think what someone else would think. In fact, I am in a different state of mind when I am downloading and looking over the waypoints I collected that particular day. Most of the time when I am traveling from place to place I am concerned about whether the device is working, how much battery life I have left, if a signal has been picked up.

\section{Day 3: Wednesday 17th August 2005}

Running late for a meeting today I noticed that I was traveling faster than normal. Not just when I was driving but my walking pace was very fast. This behavior was projected through my physical movements which were picked up in the GPS receiver. From this experience it could be possible to create user profiles on a person being tracked. For example, analyzing the walking speed can reveal an approximate walking span and from that the approximate height of the person can be deduced. This idea may seem farfetched and outlandish but it would be an interesting experiment to conduct one day.

Day 4: Thursday 18th August 2005
A thought occurred to me while I was driving to the RTA to do my driving test for my full license. What if all cars carried a GPS or similar LBS device on board and two cars were involved in a car accident. The Driver Qualification Handbook indicates that three most common types of crashes by new drivers involve two cars in rear-end collisions, adjacent collision when turning corners and opposite collisions when turning corners. A GPS could be used to reveal what exactly happened in an accident like which person hit first and which person was traveling the fastest. If cars were being tracked there could be rules set out to provide automated emergency responses. For example, if the speed of a vehicle decelerated at an alarming rate, e.g., from $100 \mathrm{~km} / \mathrm{h}$ to 0 $\mathrm{km} / \mathrm{h}$ in less than a few seconds, it would be fair to say that the vehicle was involved in an accident.

\section{Day 5: Friday 19th August 2005}

While analyzing today's tracking data I have noticed that the device sometimes loses a signal when I am driving. This is most likely due to the poor placement of the receiver. If a GPS device was used to track a person, the placement of the receiver would be very important. Parolees often have GPS devices placed around their ankles leaving it very low on the body and unable to get the best signal. I think receivers need to be placed higher up on the body to ensure continuous and accurate readings.

\section{Day 6: Saturday 20th August 2005}

The mapping software I used to download my tracking data gives the option to add and edit way points or tracking nodes. It would be easy to frame a person by editing the location data and disproving any alibi they may have. I wonder about the reliability of location data collected from GPS devices alone.

\section{Day 7: Sunday 21st August 2005}

After a week of tracking I have voluntarily decided to extend the study period of personal tracking so that I will have more data to analyze. I am not concerned about tracking my movements for another week. In fact, I am eager to continue this study to get more data and to make weekly profile comparisons possible.

\section{Day 8: Monday 22nd August 2005}

I am beginning the second week of tracking today and my awareness level of the tracking of my own movements has dulled. Throughout the day I do not consciously think of myself as being tracked. At times I may check if the device is working correctly but I am not concerned about the data the device is collecting about me. I can now say that after eight days of tracking, I am used to the process, even though it is such an abnormal activity. 
Day 9: Tuesday 23rd August 2005

After replacing the batteries in the device with a fresh set I have noticed the device picks up a signal much quicker than it did with a used set of batteries. This makes sense to me; the more power the device has the better it will work. However, this has ramifications for people being tracked, especially prisoners on parole who have to recharge the batteries each day.

\section{Day 10: Wednesday 24th August 2005}

It has occurred to me that the pervasiveness of GPS tracking depends on the complexity and detail of the GIS being used. The more information being displayed on a GIS such as landmarks, roads, side streets, the more information about the person's movements are available. When I analyze my own movements at the end of the day, I find myself sequentially and systematically recollecting where I went, and reevaluating my motives for being there.

Day 11: Thursday 25th August 2005

I have noticed that so far my data is fairly 'static', based on my weekly and daily routines. For example, I regularly travel to University and my workplace at the same time and day each week. I could also make the assumption that many people have stringent daily routines, especially people that are currently being tracked using GPS. Intelligent systems could be developed to monitor these movements automatically. The system could analyze a person's movements over a week or two and develop a personalized information system that would create user profile based on their activities.

\section{Day 12: Friday 26th August 2005}

No entry.

\section{Day 13: Saturday 27th August 2005}

The entire process of tracking my movements has become a habit. I can imagine it would be similar for any person who has to have their movements tracked. I am relieved the entire process is drawing to a close mainly because I do not have to carry around the GPS device anymore. This is not on account of the bulkiness or weight of the device (it only weighs 233 grams)- but my relief comes from the knowledge that I do not have to worry about being attached to this gadget both physically and mentally.

Day 14: Sunday 28th August 2005

Today is the final day of this study. I did not track my movements today because I stayed at home. Looking back at the previous weeks I did make an effort to travel a lot so I would have a substantial amount of data to analyze. I wonder if this will have an opposite effect on a person being tracked by a second party. Would they travel less? Would a teenager being tracked still visit places his/her parents thought of disapprovingly?

\section{Towards überveillance}

Dataveillance is defined as the "systematic use of personal data systems in the investigation or monitoring of the actions of one or more persons" [13]. M. G. Michael [14] has spoken of an emerging- überveillancean above and beyond almost omnipresent 24/7 surveillance. The problem, he has gone on to say, is that in human terms at least, "omnipresence will not always equate with omniscience, hence the real concern for misinformation, misinterpretation, and information manipulation." In the case of the civilian participant observed in this study we cannot assume everything based on his/her location. Being located in the bounds of the "home" does not mean that the participant has gone to sleep or is inactive; while he/she is at "university" it does not mean they are studying or in class; going to "work" (which happens to be a gymnasium) does not mean the civilian is working out; visiting the location of the "unibar" does not mean the civilian was drinking anything but cola; a "signal dropout" does not presume the civilian did not take a detour from their normal route; and a "speed miscalculation" does not necessarily mean the civilian was not speeding, they may have been in an alternate mode of transportation like an airplane, train or speedboat. Thus while location can be revealing, it can also be misleading. It is important that end-users of location based services, save for law enforcement, be able to "opt-out" of being tracked, rendering themselves "untraceable" for whatever reason. Being untraceable does not mean that one is doing something wrong, it is one's right to be "left alone", and LBS policies need to ensure these safeguards are built in to their applications. Being tracked by multiple "live" devices will also become an issue for the future. What is the true location of a person who is tracked by more than one device- the notion of moving and stationary association confidences is important here [15].

\section{Conclusion}

Tracking is very invasive so care must be taken to ensure that only essential information about that person is revealed. Levels of privacy can be controlled by incorporating intelligent systems and customizing the amount of detail in a given geographic information system. If these types of measures are enforced GPS tracking can be used in an ethical manner which is beneficial to the person being tracked, not detrimental. 
GPS is an effective technology and it can potentially save lives, however many current applications are not suited to it. Many groups of people rely heavily on the technology even though it is prone to inaccuracies and unreliable at times. Technological convergence may correct some of these issues but a real problem is posed if the GPS network is solely relied upon. It should be remembered that as we build more and more missioncritical applications that rely upon GPS, that the US government can shut down parts of the system in times of crisis, in addition to having already existing problems maintaining their satellites. When using any form of GPS tracking device, backup systems need to be implemented, and a Murphy's Law type mentality needs to be encouraged: If the GPS can fail, it will fail!

These findings apply to all parties which track the movements of others. These groups include police responsible for law enforcement, parole officers, caretakers of dementia patients, parents who want to track their children and employers who track their employees. These groups need to ensure that the tracking of people is done in a just and ethical fashion. It is up to the trackers to ensure that the tracking of another human is done in a way which is beneficial to the person involved and the wider community.

\section{Further research}

The next phase in this research is to carry out a group observational study. The observational study in this paper was limited to a single participant but it would be interesting to track the movements of a group of people. A study like this could be used to investigate whether detailed portfolios can be created from anonymous participants based on their travel patterns. Another aim could be to create an intelligent system that would collect and analyze the movements of people automatically. In addition to an observational study several people who have had GPS tracking imposed on them could be interviewed to ascertain the emotional and psychological consequences of having a GPS tracking device attached 24/7 for long periods of time.

\section{References}

[1] S. Duri, M. Gruteser, X. Liu, et al., "Context and Location: Framework for Security and Privacy in Automotive Telematics", Proceedings of the $2^{\text {nd }}$ International Workshop on Mobile Commerce, ACM, Georgia, 2002, pp. 25-32.

[2] K. Kayama, I.E. Yairi and S. Igi, "Semi-Autonomous Outdoor Mobility Support System for Elderly and Disabled People”, International Conference on Intelligent Robots and Systems, 2003, pp. 2606-2611.
[3] G. Pingali, R. Jain, "Electronic Chronicles: Empowering Individuals, Groups, and Organisations", IEEE International Conference on Multimedia and Expo, 2005, pp. 1540-1544.

[4] R. Cucchiara, C. Grana, and G. Tardini, "Track-based and Object-based Occlusion for People Tracking Refinement in Indoor Surveillance", Proceedings of the ACM $2^{\text {nd }}$ International Workshop on Video Surveillance \& Sensor Networks, ACM, New York, 2004, pp. 81-87.

[5] G.M. Djuknic and R.E. Richton, "Geolocation and Assisted GPS”, IEEE Computer, 2001, pp. 123-125.

[6] A. Arora and A. Ferworn, "Pocket PC Beacons: Wi-Fi based Human Tracking and Following", Proceedings of the 2005 ACM Symposium on Applied Computing SAC’05, ACM, New Mexico, 2005, pp. 970-974.

[7] H-C Wang, J-C Lin et al., "Proactive Health Care Underpinned by Embedded and Mobile Technologies", Proceedings of the Fourth Annual ACIS International Conference on Computer and Information Service, IEEE Computer Society, 2005, pp. 453-460.

[8] A. Applewhite, "What Knows Where You Are? Personal Safety in the Early Days of Wireless", Pervasive Computing, IEEE, 2002, pp. 4-8.

[9] S. Morris, A. Morris and K. Barnard, "Digital Trail Libraries”, Joint ACM/IEEE Conference on Digital Libraries, Arizona, 2004, pp. 63-71.

[10] U. Hengartner and P. Steenkiste, “Access Control to People Location Information”, ACM Transactions on Information and System Security, 8(4), 2005, pp. 424456.

[11] Robson, C. Real world research, Blackwell Publishing, Melbourne, 2002.

[12] K. Michael, A. McNamee, M.G. Michael et al. "The Emerging Ethics of Humancentric GPS Tracking and Monitoring”, International Conference on Mobile Business, IEEE, Copenhagen, 2006, in press.

[13] R.A. Clarke, "Information Technology and Dataveillance”, Communications of the ACM, 31(5), 1988, pp. 498-512.

[14] M.G. Michael, "Consequences of Innovation" in IACT 405/905 Information Technology and Innovation, Unpublished lecture notes in the School of Information Technology and Computer Science, University of Wollongong, NSW, Australia, 2006.

[15] J. Myllymaki and S. Edlund, "Location Aggregation from Multiple Sources”, The International Conference on Mobile Management, IEEE Computer Society, 2002, pp. 131-138. 